\title{
¿CAPTURADOS POR NUESTRA SUSPICACIA? ALGUNAS APROXIMACIONES ACERCA DEL ORIGEN, DESARROLLO Y EXTINCIÓN DE LAS REGULACIONES
}

\author{
Juan José Romero Guzmán*
}

\begin{abstract}
RESUMEN: En el análisis de las políticas públicas en Chile abunda la suspicacia propia de asumir la preeminencia del interés privado sobre el público, para lo cual se suele aludir al término "captura". En el presente trabajo se aspira a mostrar el recorrido académico en la búsqueda de construcciones teóricas que permitan explicar el origen, desarrollo y extinción de las políticas regulatorias. Tal ejercicio reconoce el atractivo académico de las explicaciones basadas en el interés privado, pero también subraya sus debilidades, así como la pertinencia de otras aproximaciones teóricas. De hecho, se sostiene que la influencia del poder de las ideas y la influencia de las instituciones debieran también ser tomadas en consideración. Se argumenta que las diferentes aproximaciones teóricas del fenómeno regulatorio pueden ser, hasta cierto punto, complementarias, debido al diferente nivel de generalidad con que operan. Al final, tan riesgoso como la captura del Estado, puede ser el riesgo de quedar capturados por nuestra propia suspicacia.
\end{abstract}

Palabras claves: Regulación, captura del Estado, captura regulatoria, políticas públicas, interés privado, interés público, ideas e instituciones.

ABSTRACT: In the Chilean public policy discussion it is usual the suspicion of assuming the preeminence of private interest above public interest. From this perspective, the term "capture" is often alluded. This paper aspires to show the academic path in search for theories that allow explaining the origin, development and extinction of regulatory policies. Such exercise recognizes the academic attractiveness of private interest explanations, but also underlines its weaknesses as well as the pertinence of other theoretical approximations. In fact, it is said that the power of ideas and the influence of institutions should also be taken into consideration. It is argued that different theoretical explanations of the regulatory phenomenon could act, to some extent, in a complementary fashion because of their different levels of generality. At the end, as risky as the state capture it could be the risk of being capture for our own suspicion.

Key words: Regulation, state capture, regulatory capture, public policy, private interest, public interest, ideas and institutions.

\footnotetext{
* Abogado. Licenciado en Derecho, Pontificia Universidad Católica de Chile. Master of Science in Regulation, The London School of Economics and Political Science (University of London), Profesor curso "Derecho, Economía y Mercado" y "Regulación de mercados" en pregrado, y "Derecho Constitucional y Regulación Económica”, en postgrado, Pontificia Universidad Católica de Chile.
} 


\section{INTRODUCCIÓN}

En los últimos años y, con particular fuerza, en los últimos meses, Chile ha sido testigo de la irrupción en la agenda pública del tema de los conflictos de interés ${ }^{1}$. El vigor con que parece haber penetrado en la ciudadanía el deseo por mayores niveles de transparencia ha ido de la mano con un creciente escepticismo respecto de las motivaciones de interés público con que se desarrollaría la función o servicio público ${ }^{2}$.

Hoy, es posible advertir en la prensa cómo se ha colocado en entredicho la forma con que se asignan los cargos públicos, así como los encargos a privados de tareas de relevancia para la satisfacción del interés público. En el último tiempo se ha hablado de nepotismo y se ha vuelto a poner en tela de juicio la forma en que las empresas públicas desempeñan sus funciones ${ }^{3}$. Nuevamente han comenzado a adquirir notoriedad tópicos tales como la declaración patrimonial de intereses por parte de parlamentarios y miembros del Ejecutivo, el fideicomiso ciego, la probidad y el acceso a la información pública, la regulación del lobby, el reestudio de la regulación del financiamiento de las campañas políticas, etc. ${ }^{4}$.

La relación entre el dinero y la política y su necesidad de regulación ha pasado a ser un lugar común en la discusión pública, del mismo modo en que el término "captura" o "captura regulatoria" ha pasado a ser parte del vocabulario obligado de los interesados en los temas de políticas públicas. Subyacente a este tipo de temas se encuentra, en último término, la idea de preeminencia del interés privado por sobre el público.

El escenario aludido con anterioridad no es uno en que abunde la ingenuidad. Muy por el contrario, se trata de uno en que predomina la suspicacia. La carga de la prueba parece haberse invertido. Para explicarse la génesis de políticas públicas y regulaciones, así como su implementación y fiscalización, pareciera resultar un tanto naivë descansar en el supuesto de que los actores involucrados estarían actuando únicamente teniendo como norte la satisfacción del interés público. Por ejemplo, si bien para intentar explicar y justificar la intervención del Estado en la economía aún se alude a la expresión "falla del mercado" (market failure), la cual sería indicativa de aquellas circunstancias que ameritarían la intervención reguladora del Estado remediando las imperfecciones del mercado, también se suele aludir, con especial ahínco en otras latitudes, a lo que podría denominarse como "fallas del Estado" o "fallas del Gobierno". Estos últimos

\footnotetext{
${ }^{1}$ Ver, por ejemplo, la profusa difusión en los medios de comunicación del caso de la multa impuesta por la Superintendencia de Valores y Seguros (en virtud de resolución № 306 fechada el 6 de julio de 2007) en contra del ex candidato presidencial Sebastián Piñera y la discusión sobre el grado de compatibilidad entre la actividad política y la actividad empresarial.

${ }^{2}$ Los resultados de la última encuesta CEP (julio de 2007) resultan ilustrativos del bajo nivel de aprobación por parte de la ciudadanía de la actividad política.

${ }^{3}$ La controversia pública respecto de los beneficiados con la beca Presidente de la República y su supuesta vinculación familiar con altos personeros de los gobiernos de la actual coalición gobernante y el escándalo derivado de la información sobre la gestión de la Empresa de Ferrocarriles del Estado constituyen ejemplos recientes.

${ }^{4}$ Respecto de todas estas materias existe, en la actualidad, una ley de reciente vigencia (como en el primero de los casos), un proyecto de ley, o un anteproyecto de ley de discusión interna en el gobierno (como en el caso del fideicomiso ciego).
} 
tipos de fallas colocan el acento en las fallas o fracasos de aquellas regulaciones dirigidas, real o aparentemente, a corregir las imperfecciones de determinados mercados, lo cual ha llevado a distanciarse de la hipótesis consistente en que la intervención reguladora del Estado siempre puede ser explicada en base a causas o motivaciones de interés público.

En un escenario en donde predomina un vocabulario con expresiones como "conflicto de interés", "captura”, "corrupción”, entre otras, se encuentra implícito un descrédito de las actuaciones basadas en el "interés público" y, por el contrario, una creciente inclinación por explicarse la realidad en general y las políticas públicas y regulaciones en particular, en base al predominio de los intereses privados. El objeto del presente artículo consiste, precisamente, en repasar las diferentes causas, motivaciones o explicaciones que se han dado para entender el fenómeno regulatorio y su origen, desarrollo y reforma. Al intentar una explicación de la génesis de las políticas públicas y regulaciones (incluida las leyes), así como de su implementación y fiscalización, cabe hacerse una pregunta fundamental: ¿Merecen estar las explicaciones de la regulación basadas en el interés público desacreditadas? Una respuesta a la interrogante planteada obliga, entre otras cosas, a tratar el tema de la captura regulatoria como reflejo del predominio del interés privado por sobre el público en el devenir de la actividad política y pública, lo cual nos lleva a intentar colocar líneas de pensamiento y términos de moda en su debida dimensión y perspectiva. En último término, el análisis propuesto nos obligará a preguntarnos si no estaremos, acaso, siendo capturados por nuestra propia suspicacia de ver en todo o casi todo una preponderancia del interés privado por sobre el público y, por ende, de explicarse la realidad, particularmente el estado actual de nuestro régimen regulatorio, como un subproducto del interés pecuniario o privado de los actores involucrados.

El presente artículo, en primer lugar, describirá someramente en qué consiste la formulación de la teoría del interés público de la regulación. En segundo lugar, se expondrán las principales críticas a la teoría del interés público. En tercer lugar, se reseñarán las líneas de pensamiento fundamentales de las teorías de la regulación basadas en el interés privado. En cuarto lugar, se ilustrarán algunas aplicaciones de la teoría precedentemente aludida en el análisis de políticas públicas. En quinto lugar, se hará un análisis crítico de las teorías del interés privado. En sexto lugar, se examinarán las explicaciones basadas en el poder de las ideas y de las instituciones. En séptimo lugar, se intentará responder a la interrogante de hasta qué punto la teoría del interés público de la regulación se encuentra desacreditada, para, finalmente, en octavo lugar, ensayar una conclusión.

\section{FORMULACIÓN DE LA TEORÍA DEL INTERÉS PÚBLICO DE LA REGULACIÓN}

La teoría del interés público o funcionalista de la regulación, la cual fue la prevaleciente hasta comienzo de los años sesenta, plantea que la motivación o explicación de la intervención del Gobierno o del Estado en los mercados descansa, principalmente, en las fallas del mercado. En efecto, cuando la economía de mercado opera ineficientemente, como cuando hay problemas relacionados con el poder monopólico; cuando existen problemas de información; cuando se dan problemas de coordinación; cuando se está en presencia de externalida- 
des; cuando se presentan inconvenientes relacionados con la existencia de bienes públicos o de recursos comunes; o, incluso, cuando se presentan inequidades de acuerdo con los sentimientos populares prevalecientes, por nombrar fallas de mercado típicamente mencionadas 5 , habrá, prima facie, desde el punto de vista del interés público, un caso o justificación para una intervención regulatoria ${ }^{6}$. Como se ha hecho notar por algunos autores, de acuerdo a la teoría del interés público de la regulación, al menos en su formulación original, "detrás de cada diseño de regulación podría ser descubierta una imperfección de mercado, la existencia de la cual proporciona una completa justificación para alguna regulación sobre la que se asume su operación efectiva y sin costo" ${ }^{\text {. }}$.

La teoría del interés público representa una aproximación normativa donde las justificaciones convergen con las explicaciones del proceso regulatorio ${ }^{8}$. Más aún, esta teoría asume que los programas regulatorios están bien inspirados y que los reguladores buscan de buena fe la satisfacción del interés público tal como se define en las leyes o reglamentos en que se expresan. De acuerdo a esto, aunque incluso las evidencias empíricas muestren algunos desempeños regulatorios desilusionantes, tal como claramente es posible encontrar en la realidad, la falla o fracaso tendría su explicación en un mal manejo de las entidades reguladoras, las cuales, además, son instadas a acometer tareas muy dificultosas?

\section{PRINCIPALES CRÍTICAS A LA TEORÍA DEL INTERÉS PÚBLICO}

La visión benevolente de la regulación gubernamental o estatal en la cual la teoría funcionalista se basa ha sido acusada de ingenuidad. Como Hood explica, esta clase de interpretación de la regulación implica "una visión del gobierno como un desapasionado 'super-capitalista', inspirado solamente por un interés en la viabilidad de largo plazo del

\footnotetext{
5 Para una sistematización de las fallas de mercado habituales que pueden dar origen a la intervención reguladora del Estado ver, entre otros, a BREYER (1982) pp. 15-35; OGUS (1994) pp. 29-54; y SUNSTEIN (1990) pp. 47-73.

${ }^{6}$ Ver a OGUS (1994); Ogus (2004). Dicho autor enfatiza que, desde el punto de vista del interés público, no basta una falla de mercado para que se justifique la intervención reguladora del Estado, sino que tiene que ponderarse la primera circunstancia con los costos que involucraría esta última. Este tipo de apreciación difiere un poco de planteamientos tempranos de visiones funcionalistas o del interés público de la regulación (comúnmente asociadas a la economía del bienestar), las cuales prestaban una menor atención a los costos o fallas del regulación o de los gobiernos.

7 Posner (1974) p. 336. Ogus y VeljANOVSKi (1984) p. 241, aluden, también, a las palabras de Richard Posner. 8 MAJONE (1996) p. 29 afirma el carácter normativo, valorativo o teleológico de esta teoría, lo cual ratificamos. No obstante, hay algunos autores que se refieren a ella como una de carácter positivo en vez de normativa OGUS (2004) y DEN HeRTOG (2000).

9 Al hacer referencia a la Teoría del Interés Público, hay comentaristas, como DEN HerTOG (2000) pp. 232-235. que distinguen entre una versión antigua y una nueva de dicha teoría. Por ejemplo, se destaca como supuesto de la mencionada teoría (en su elaboración más temprana) la eficiencia de toda intervención reguladora dirigida a remediar una falla de mercado. Como complemento a lo anterior, se suele hablar de "una versión más sofisticada de la Teoría del Interés Público", en el cual se toma en consideración los eventuales costos y fallas de la regulación.
} 
sistema de mercado y más capaz de identificar y corregir las debilidades del mercado que otros actores"10. Además, esta aproximación funcionalista o de interés público ha sido también criticada de ser sumamente teleológica e incapaz de explicar la génesis o concepción de las políticas regulatorias en el mundo real. De hecho, la aludida teoría solamente proveería una base para reconocer las oportunidades en donde los gobiernos debieran intervenir, proporcionando las justificaciones para aquello ${ }^{11}$. Esta no consideraría la descripción de las consecuencias de los programas gubernamentales o la naturaleza del proceso de génesis de las políticas públicas que da lugar a cualquier programa regulatorio. En otras palabras, esta teoría tendría un muy limitado poder explicativo. Como lo manifestara Peltzman, "un buen economista no necesita más de quince minutos para construir una falla de mercado para 'explicar' cualquiera de esas intervenciones [regulatorias]" 12 .

La crítica de dejar varios aspectos de la regulación sin explicación y de carecer de realismo ${ }^{13}$, ha dado lugar a argumentar, por parte de algunos, que "el análisis normativo es irrelevante debido a que los resultados de las políticas depende de factores tales como las reglas del proceso político, los incentivos que enfrentan los diferentes participantes del proceso y la cambiante configuración de poder e intereses en la sociedad, más que en consideración a la eficiencia asignativa o a ideas acerca del interés público" ${ }^{14}$. En efecto, cabe preguntarse por qué, en un mundo de actores privados egoístas y pecuniariamente interesados, los funcionarios públicos (de entre toda la gente) serían capaces y estarían deseosos de actuar en una manera altruista ${ }^{15}$. En fin, ¿no será más plausible, acaso, mirar la regulación gubernamental como un producto del interés personal de políticos y burócratas, aliados con grupos de interés o presión? ${ }^{16}$.

\section{LÍNEAS DE PENSAMIENTO FUNDAMENTALES DE LAS TEORÍAS DE LA REGULACIÓN BASADAS EN EL INTERÉS PRIVADO}

George Stigler, premio Nobel de Economía, planteaba que "[s]i el interés propio domina a la mayoría de los seres humanos en todas sus transacciones comerciales; ¿por qué no también en todas sus empresas políticas? (...) ¿Calculan los hombres con lógica y objetividad en cuestiones monetarias, pero con confusión y amor en cuestiones electorales?" 17.

La aproximación general aludida precedentemente, abiertamente escéptica de la ocurrencia de acciones humanas y colectivas guiadas por la promoción del bien común por sobre el individual, ha resultado ser muy influyente desde la época de los sesenta y setenta, y su cuna ha sido, fundamentalmente, la escuela de la elección pública (public choice), identificada claramente con lo que ha pasado a conocerse como la "escuela de

\footnotetext{
${ }^{10}$ HOOD (1994) pp. 20-21.

11 MAJONE (1996) p. 29.

12 Peltzman (1989) p. 17

13 STIGLER (1971a) p. 18. se refiere a la "visión idealista de la regulación pública".

${ }^{14}$ MAJONE (1996) pp. 29-30.

15 HOOD (1994) p. 21.

16 HOOD (1994) p. 21.

17 STIGLER (1971b) p. 55. (La traducción realizada por el libro recién citado ha sido alterada por mí en la última oración, por estimarla más fidedigna con la original en inglés).
} 
Virginia"18, y la escuela de economía de la Universidad de Chicago en EE.UU., fuentes de numerosos e importantes trabajos académicos que han dado lugar a una importante cantidad de galardonados con el premio Nobel de Economía ${ }^{19}$.

Sin embargo, el más conocido de los primeros intentos teóricos por explicar los fenómenos regulatorios desde la óptica del interés privado por sobre el público y en el que se invoca el tema de la captura regulatoria fue aquel que se conoce como la teoría del "ciclo de vida" y que forma parte de lo también conocido como la "teoría clásica de la captura"20. En una publicación de 1955 titulada "Regulating Business by Independent Commission"21, Bernstein plantea que una vez que un ente regulador está recién establecido tiende a atraer la atención pública y actúa con vigor, pero que cuando la atención pública se desplaza hacia otros temas, dicho respaldo público comienza a declinar y la agencia reguladora queda vulnerable a la dominación por los intereses de los regulados.

La noción de captura introducida por estas aproximaciones teóricas tempranas (en las cuales destaca la aludida precedentemente) y que fueron elaboradas principalmente por cientistas políticos, asumían, en términos generales, que con el transcurso del tiempo la regulación terminaría por servir los intereses de aquel segmento de la industria involucrado. Se asumía, a modo ilustrativo, que ante un mal uso de la posición económica de poder por parte del segmento de la industria correspondiente, los legisladores la sujetaban a niveles de regulación más exigentes. Con el transcurso del tiempo aparecían otras prioridades políticas en la agenda pública y el monitoreo de los entes reguladores por parte de los legisladores se iba relajando. Ante esto, la agencia reguladora tendía a evitar los conflictos con la compañía regulada, respecto de la cual tenía cierta dependencia en términos de información, además de la eventual oportunidad laboral que para los reguladores significaban las empresas bajo su fiscalización, lo cual daba lugar, en el tiempo, a que las entidades reguladoras terminaran sensibilizándose y representando los intereses de la industria bajo su vigilancia ${ }^{22}$.

\footnotetext{
${ }^{18}$ En dicha "escuela" se entienden integradas las universidades George Mason, Virginia-Tech y la University of Virginia.

19 Por nombrar algunos relacionados con el tópico que nos interesa, piénsese en James Buchanan (escuela de Virginia), y George Stigler y Gary Becker (escuela de Chicago).

${ }^{20}$ En estricto rigor, esta teoría de la captura mezcla una visión funcionalista o de interés público (particularmente al principio del ciclo de vida de las entidades reguladoras), para luego dar lugar a una preeminencia del interés privado una vez capturadas o pervertidas. Debe tenerse presente que la teoría económica de la regulación (incluidas sus diferentes variaciones) popularizada por STIGLER, PELTZMAN y otros, fue conocida, también, como teoría de la captura.

21 Bernstein (1955) y Posner (1974) agrupan la contribución de Bernstein dentro de lo que él considera la versión de los cientistas políticos de la captura, p. 341.

${ }^{22} \mathrm{La}$ literatura fue describiendo varios medios o instancias hipotéticas utilizadas para influenciar el actuar del ente regulador, entre los que se mencionan los siguientes: (i) la información requerida por la entidad reguladora puede ser obtenida solo de las industrias reguladas (asimetría de información); (ii) la carencia de especialización en los tópicos puede dar lugar a que la agencia reguladora tenga que reclutar gente de aquellas industrias; y (iii) la industria puede amenazar con costosos y largos recursos judiciales, aunque sea por cosas triviales, evitando ser cooperativa. Ver al respecto a OGUS (1994) y para una reflexión actual de cuándo puede considerarse que un regulador ha sido capturado o no, ver a LEVINE (1998).
} 
La teoría de la captura, daba, sin embargo, lugar a muchas interrogantes sin contestar. Por ejemplo, ¿por qué debieran solo las agencias reguladoras constituir el objetivo y sucumbir, consiguientemente, a la captura? ¿Si un grupo de interés es lo suficientemente poderoso como para pervertir una agencia, por qué no vuelca, entonces, su atención hacia los políticos intentando, de esta manera, influenciar la regulación? ${ }^{23}$.

No obstante los intentos teóricos anteriores, fue en el marco de la llamada "Teoría Económica de la Regulación”, propuesta y desarrollada, fundamentalmente, en el seno de la escuela de Chicago $^{24}$ (a lo que es posible agregar la aproximación de la escuela de Virginia, dentro del marco de lo que se conoce como Teoría de la Elección Pública ${ }^{25}$ ) donde se dio "rienda suelta" a un cúmulo de estudios abiertamente críticos de la regulación existente ${ }^{26}$. Esta teoría busca formular una concepción analítica general que permita explicar y predecir las regulaciones e, incluso, como en el caso de la "elección pública", las decisiones colectivas en general. En efecto, se pensaba que el crecimiento de la regulación y sus persistentes fallas no podía deberse a coincidencias ni hechos aislados, sino que debía haber una explicación más convincente que aquellas basadas en el interés público o que aquellas que, aludiendo a la posibilidad de captura, resultaban ser demasiado "tímidas" y restringidas en su ámbito. En otras palabras, lo que se necesitaba, para sus proponentes, no era otra cosa que una teoría general que pudiera explicar cómo los intereses privados operan en el dominio público ${ }^{27}$.

Es aquí, como se dijo, cuando emergen los economistas y su teoría económica de la regulación, así como la teoría de la elección pública, las cuales critican una supuesta visión bifurcada del comportamiento humano que, a modo ilustrativo, asuma que "los individuos que entran a un supermercado y compran la mercadería que han elegido, cuando entran a la cámara de votación lo hacen no por los políticos y leyes que los beneficiarán, sino por las políticas y leyes que beneficiarán a la nación en su conjunto" ${ }^{28}$. Para estos teóricos, aquel votante que sufraga en la cámara de votación es la misma persona que aquel cliente de supermercado.

De acuerdo a la Teoría Económica de la Regulación, habría un mercado por la regulación, toda vez que la existencia y forma de la regulación puede ser predicha como respuesta por los políticos a las demandas de los grupos de interés, quienes se verán, en definitiva, beneficiados por las medidas regulatorias por ellos buscadas. Dada las ventajas de la homogeneidad de intereses y los relativamente bajos costos de organización, las agrupaciones de productores (o empresariales) serán capaces de ejer-

\footnotetext{
${ }^{23}$ Ver en especial a POSNER (1974) pp. 341-342. Para una síntesis de las críticas ver a OGUS (1994) p. 58 y a Den Hertog (2000) p. 236.

${ }^{24}$ Y por lo mismo conocida, también, como "The Chicago Theory of Regulation".

25 Con un distinto nivel de identificación, es posible incluir a ambas escuelas dentro de la corriente de pensamiento que se conoce como Elección Pública.

${ }^{26}$ A este respecto, la "Journal of Law and Economics" editada por la Universidad de Chicago tuvo un rol significativo.

27 Ogus (1994) p. 58.

28 TULLOCK et al. (2002) p. 5.
} 
cer más influencia que aquellos que representan a los consumidores o ideologías ${ }^{29}$. Por consiguiente, y en palabras de Stigler, su precursor, "la tesis central es que como regla, la regulación es adquirida por la industria y es diseñada y operada primeramente para su beneficio" 30 .

Evidentemente, esta teoría busca proporcionar una explicación no solo para aquellas regulaciones que abiertamente confieren beneficios a los productores (por ejemplo, a través de subsidios monetarios), sino también para medidas que ostensiblemente protegen intereses más generalizados, como la protección de los consumidores o el medio ambiente, pero que sirven, en último término, para generar ganancias para las industrias o compañías que son reguladas ${ }^{31}$. Por ejemplo, algunas de las medidas pueden elevar las utilidades de aquellas empresas que operan en el mercado (incumbents) si ellas restringen la entrada de nuevos participantes o competidores, o hacen más oneroso su desenvolvimiento. Se hizo notar que los mecanismos muchas veces eran sutiles y, casi siempre, presentados a la opinión pública bajo un halo de interés público, como ocurría con regulaciones supuestamente protectoras de los consumidores o del medio ambiente ${ }^{32}$.

Con alguna diferencia con la aproximación sustentada por la escuela de Chicago (asumiéndose las variaciones entre diferentes de sus exponentes), la escuela de Virginia (más fuertemente asociada a la línea de pensamiento conocida como Elección Pública) adopta una mirada más normativa que predictiva. A lo anterior, se suele destacar un supuesto mayor énfasis en el tema de la eficiencia, así como en la actuación de los agentes políticos ${ }^{33}$.

\footnotetext{
${ }^{29}$ Aquí STIGLER basó su argumentación en el trabajo de OlSON (1965), quien en su obra "The Logic of Collective Action: Public Goods and the Theory of Groups" intenta explicar por qué algunos grupos son capaces de ejercer mayor influencia que otros respecto de las políticas de gobierno. OlsON explica que mientras más bajos sean los costos de transacción y los problemas relacionados con los free-riders o polizontes, más eficientes serán los grupos de interés en alcanzar sus objetivos, algo que es más fácil que ocurra con aquellas organizaciones más pequeñas y con intereses más homogéneos.

30 STIGLER (1971) p. 1. Cabe hacer notar que destacados exponentes de la escuela de Chicago han desarrollado variaciones más o menos significativas al planteamiento inicial de Stigler. Entre los trabajos trascendentales en esta línea se encuentran el de PELTZMAn (1976) y BECKER (1983).

${ }^{31}$ Ogus (1994) pp. 71-72.

${ }^{32}$ Hay muchos casos en que una medida reguladora puede tener un efecto anticompetitivo. Por ejemplo, supóngase que una legislación prohíbe ciertos procesos productivos sobre la base de sus dañinos efectos contaminantes, pero que para minimizar los costos de aquellos que ya usan tal proceso, la prohibición se aplica solo a las nuevas plantas productivas. En este caso, claramente la legislación constituiría una barrera a la entrada que, como tal, generaría beneficios para los productores existentes. Una regulación también puede ser anticompetitiva si los costos de cumplir con ella son proporcionalmente superiores para una compañía pequeña que para una grande, como ocurriría si los costos son similares cualquiera que sea el nivel de producción de la industria. Esto último suele ocurrir preferentemente con estándares que especifican, por ejemplo, la tecnología a usar, criterio de la mejor tecnología disponible, ya que por efecto de economías de escala, su introducción puede ser más barata para las grandes firmas que para las pequeñas. Ver a Ogus (1994).

33 Ver a Den Hertog (2000) pp. 243-244 y a Ogus (2004) p. 38. Para un análisis de las muchas similitudes, así como de algunas diferencias entre la escuela de Chicago y la de Virginia, véase a MITCHELL (2001) pp. 3-33. Cabe hacer notar, sin embargo, que una de las críticas que se le hace a la aproximación comentada en su insuficiente explicación de los procesos políticos e instituciones.
} 
No obstante lo anterior, y más allá de las distinciones susceptibles de hacerse entre uno y otro exponente o una u otra escuela, resulta importante hacer notar el cambio que significó la visión en virtud del cual los economistas no solo comenzaron a examinar aquello que era lo típico de su disciplina, cual es el funcionamiento del mercado (es decir, el juego de las preferencias individuales), sino que se abocaron (y lo siguen haciendo en la actualidad) al análisis económico de la política ${ }^{34}$. En lo que se suele describir como una invasión de la ciencia política por los economistas, estos tratan de explicar o describir cómo las preferencias individuales se reflejan en las decisiones adoptadas por instituciones de decisión colectiva (políticas), y evaluar, normativamente, las consecuencias para el bienestar social. Para esto, ellos asumen que el comportamiento en la arena política no es, en esencia, diferente del comportamiento en el mercado. Los individuos actúan en ambas instancias racionalmente en orden a maximizar su utilidad. Esto significa, por una parte, que los ciudadanos y los grupos de interés usan su poder de voto para extraer de los órganos de decisión colectiva el máximo beneficio para ellos, y, por otra, que los políticos y partidos políticos actúan como empresarios que suministran aquellos beneficios a cambio de que voten por ellos ${ }^{35}$.

Uno de las principales ideas de la Teoría de la Elección Pública es que, entre elecciones, las políticas de gobierno se encuentran fuertemente influenciadas por las presiones de los grupos empresariales, lo que se reflejaría en aquella tendencia en virtud de la cual las políticas públicas son afectadas más por los organizados productores o empresarios que por los generalmente desorganizados consumidores. Los grupos empresariales, bajo esta óptica, esperarían altos retornos de sus labores de lobby debido a que mientras los favores que ellos recibirían del gobierno se concentrarían en sus miembros, los costos se dispersarían suficientemente sobre la comunidad en general. En consecuencia, dado lo anterior, dichos grupos de interés tendrían un incentivo para invertir sustanciales recursos en actividades de lobby ${ }^{36}$.

\section{LA APROXIMACIÓN BASADA EN LA PREDOMINANCIA DEL INTERÉS PRIVADO POR SOBRE EL PÚBLICO Y EN LA NOCIÓN DE CAPTURA EN EL DISCURSO PÚBLICO CHILENO RECIENTE}

Hoy, esta manera de pensar o explicarse la regulación sobre la base de la dominación del interés privado sobre el público sigue vigente. En efecto, ante el hecho indesmentible de que la regulación falla (a veces igual o peor de lo que ocurre con el

\footnotetext{
${ }^{34}$ En este ultimo aspecto ha sido reconocido el influyente trabajo de DowNS (1957).

35 Para una aproximación preliminar a la teoría de la elección pública ver, por ejemplo, a TULLOCK et al. (2002). Para exposiciones más avanzadas ver, entre otros, a MUELLER (2003).

36 En otras palabras, "[1] os grupos de interés, los burócratas y los políticos, solos o en combinación, pueden y de hecho manipulan el proceso político por ganancias personales a expensas del bienestar general. Los grupos de interés ganan del desalineamiento entre los 'beneficios concentrados' que ellos buscan y los costos difusos que ellos imponen, y de las ganancias para los políticos o burócratas del mutuo intercambio de favores" MCLEAN (1987) p. 52. Citado por SELF (1993) p. 58.
} 
mercado) se suele mirar con escepticismo las explicaciones o versiones "rosas" de las causas de su fracaso ${ }^{37}$. La suspicacia domina el escenario.

La captura, el poder económico y el poder político son términos y temas actuales. No son pocos los artículos académicos y las columnas de opinión en los que se enfatiza el tema de la captura regulatoria, la captura del Estado y la influencia del poder económico sobre el poder político.

Una primera línea temática en el discurso público chileno actual, tributaria del perfil de pensamiento popularizado por las teorías del interés privado, es aquella fuertemente suspicaz y temerosa de la captura ejercida por el poder económico o empresarial respecto de las instituciones o instancias de decisión pública.

En general, el análisis desplegado es uno más normativo que explicativo y la argumentación es más teórico-lógica que basada en datos empíricos comprobados. El foco principal de carácter general ha sido la discusión sobre la relación entre el dinero y la política. En particular, es posible distinguir diversos temas, entre los cuales se puede mencionar el del financiamiento electoral, el relativo al lobby y aquel relacionado con los conflictos de interés.

En lo referente al financiamiento de las campañas políticas, por ejemplo, Eduardo Engel ha escrito numerosas columnas de opinión en donde advierte del riesgo de captura regulatoria por parte del poder económico ${ }^{38}$. Dicho autor es particularmente crítico de que se permita a las empresas realizar donaciones políticas ${ }^{39}$; de que una parte de las donaciones (y más allá de las restricciones establecidas) puedan ser confidenciales ${ }^{40}$; de la falta de capacidad fiscalizadora del Servicio Electoral, el cual debiera ser no solo el receptor de los dineros, sino también quien realice los gastos electorales en representa-

\footnotetext{
37 Un grupo de respuestas se centraban en aquello que podría ser descrito como "falla técnica": insuficiente experiencia o especialización; insuficiencia de recursos; información inadecuada; falla en anticipar importantes efectos colaterales de los instrumentos regulatorios usados; inadecuado sistema de fiscalización; casos en que el gobierno y el Parlamento tenían que responder rápidamente a amplios llamados por acción luego de algún desastre o evento que haya capturado la atención pública. Etc. Una interesante tipología de cómo la regulación puede fallar, en que se contienen razones adicionales a la posibilidad de captura por grupos de interés nos la proporciona SUNSTEIN (1990) pp. 74-110.

${ }^{38} \mathrm{La}$ idea de captura la utiliza no solo en sus artículos referentes al financiamiento electoral. Respecto de este último tema, sin embargo, pueden verse las siguientes columnas: "Financiamiento político y captura del Estado" (ENGEL: La Tercera, 19/1/03); "No adivinen quién viene a cenar" (ENGEL: La Tercera, 8/6/03); "Dinero y política - el efecto Jeffords" (ENGEL: La Tercera, 15/2/04); "Se necesita, urgente, una contraparte" (ENGEL: La Tercera, 11/4/04).

39 Engel (La Tercera, 31/7/2005) sostiene que "son los ciudadanos los que votan (...) [siendo] importante limitar el impacto negativo que tienen sobre las políticas públicas los distintos grupos corporativos". En una visión opuesta desde el punto de vista técnico puede verse, por ejemplo, a Harald BEYER ("Mitos sobre financiamiento político", El Mercurio, 7/8/2005).

${ }^{40}$ Criticando la actual regulación de las campañas políticas, ENGEL ("Se necesita, urgente, una contraparte", La Tercera, 11/4/2004) ha sostenido insistentemente, por ejemplo, que "las donaciones reservadas no evitan la captura ni la extorsión", principal temor justificatorio de su existencia. Según él, "[L]os grandes financistas cuentan con diversas alternativas para comunicar a un candidato que han hecho una contribución sustantiva a su campaña". Lo manifestado por el autor recién aludido fue comentado y criticado por Salvador Valdés en "Desmintiendo a Engel”, La Tercera, 18/4/04 y en "Réplica a Engel”, La Tercera, 2/5/ 2004, en el cual se hacer ver, en opinión del autor, los prejuicios poco académicos del primero.
} 
ción de los candidatos, etc. ${ }^{41}$. Este argumenta, en síntesis, que "al permitir que las empresas financien la política se facilita la captura del Estado" 42 .

El tema de la regulación del lobby está inspirado, en parte, por similares aprensiones. El ya citado Engel, junto a Daniel Kaufmann, en una larga columna o artículo de opinión llamaban la atención respecto del lobby e influencia indebida como una tarea pendiente para Chile ${ }^{43}$. Enfatizándose líneas argumentales sustentadas por el mismo Kaufmann en trabajos académicos ${ }^{44}$, se hacía hincapié más que en los actos ilegales, en la actividad de aquellos grupos corporativos que, sin que involucren necesariamente actos ilícitos, pueden tener una influencia indebida desmedida sobre la autoridad. En definitiva, se advertía respecto de los peligros de la "privatización de la política pública" ${ }^{45}$.

Otro debate afín es aquel relacionado con la regulación de los conflictos de interés, el cual ha estado presente por mucho tiempo en la agenda pública. Un reportaje de comienzos del año 2007 destacaba, sin embargo, los "lentos avances en deslindar política y negocios". Como bien se resume en dicho artículo de prensa, "van años de discusión sobre cómo evitar conflicto de intereses cuando se ejerce un cargo público. Se ha avanzado, pero la relación política-negocios sigue como un área rara que sirve para descalificar a empresarios-candidatos y a dirigentes políticos-empresarios. El gobierno envió iniciativas sobre inhabilidades, pero no puso entre sus prioridades el antes urgente proyecto de fideicomiso ciego, planteado previo a las elecciones 2005, para empresarios que entran a la vida pública" 46 . Dentro del tópico aludido, podrían, a modo ilustrativo, distinguirse diversos subtemas como la exigencia de declaración patrimonial (algo legislado al día de hoy); el ya aludido fideicomiso ciego; la dedicación exclusiva para el ejercicio del cargo de parlamentario ${ }^{47}$; las inhabilidades para ex funcionarios públicos para realizar, con posterioridad, actividades en sectores antes regulados por ellos (el problema de la puerta giratoria o revolving door $)^{48}$; etc.

En materia de institucionalidad reguladora, por nombrar otro tópico a propósito del antiguo fenómeno conocido como revolving door o puerta giratoria, ocurre lo mismo. En el análisis de los diseños institucionales más adecuados para el sector de servicios económicos básicos (utilities) se discute, recordándonos lo analizado en la década del cincuenta del siglo pasado por Bernstein, cuál es el mejor arreglo institucional que evite

\footnotetext{
${ }^{41}$ Además de las columnas aludidas en la nota anterior, ver a ENGEL ("Platas negras en las campañas", $L a$ Tercera, 31/7/2005).

${ }^{42}$ ENGEL ("Se necesita mejor información para legislar", La Tercera, 5/4/2004).

43 ENGel y KaUfmann ("Lobby e influencia indebida: una tarea pendiente", Revista Qué Pasa -Anuario 2004-, 18/12/2004).

44 Ver a Hellman y Kaufmann (2002), y Kaufmann y Vicente (2005).

45 En materia de lobby ver los siguientes proyectos de ley: Boletín 3407-07 (5/11/2003) y Boletín 3498-07 $(7 / 12 / 2004)$

46 "Lentos avances en deslindar política y negocios", El Mercurio, C6, 12/3/2007.

47 Ver, a este respecto, a Patricio NAVIA ("Los Legisladores part-time", La Tercera, 16/4/2006).

48 Ver proyectos de ley que amplían restricciones fijadas en la Ley Orgánica Constitucional de Bases de la Administración del Estado en materia de inhabilidades de ex funcionarios públicos: Boletín 4376-06 (01/ 08/2006) y Boletín 4076-06 (17/01/2006).
} 
la posibilidad de captura de la entidad, sea esta por parte de las empresas o por parte del mismo poder político central (tema general que se verá más adelante) ${ }^{49}$. No es casualidad, independiente de su mérito, que una de las sugerencias más socorridas sobre la materia sea abogar por entidades regulatorias más autónomas o independientes ${ }^{50}$.

Lo interesante de destacar es, nuevamente, el ya antiguo temor por la cooptación o captura de los reguladores o legisladores por parte de los grupos de interés, en especial del empresariado. En un escenario argumentativo en que no es fácil entrar en distinciones, sutilezas y contextualizaciones sobre qué es lo que realmente debiera preocupar de los conflictos de interés y de cómo abordarlo ${ }^{51}$, el reconocimiento del grave riesgo de captura del poder político por parte del poder económico, como un fenómeno de ocurrencia casi inevitable, se ha ido imponiendo como lugar común y, en algunos casos, cabría preguntarse si también como dogma de fe.

Más allá de la discusión que pueda haber respecto del valor argumental que en sí mismo pueda tener de la noción de captura y de la magnitud de su sustento empírico, no puede desconocerse que es un fenómeno cuya eventual ocurrencia merece tenerse en consideración desde un punto de vista normativo. Ilustrativo de la preocupación actual por el tema es la siguiente declaración del ministro de Obras Públicas: "[A]quí hay poderes fácticos en todos los ámbitos. Desde el control de la prensa a la influencia de los negocios en el mundo de la política. Y el desafío de un gobierno que responde a los ciudadanos es que las decisiones finales respondan más a los intereses de la gente que a la presión de grupos de interés. Ese es el desafío. Y no estoy diciendo algo trivial, sino algo muy de fondo: tenemos que trabajar para el interés colectivo y evitar ser capturados por los intereses corporativos" 52 . Paradójicamente, meses después de la entrevista citada, el mismo ministro (un respetado académico) se vio cuestionado por un supuesto conflicto de interés que tendría en razón de haber sido ex director de una empresa de transmisión eléctrica involucrada en un proyecto en el cual la decisión del ministerio a su cargo

${ }^{49}$ Ver artículo del Instituto Libertad y Desarrollo (1999).

50 Ver a SAAVEDRA y SOTO (1999). Igualmente, ver a PAREDES et al. (1998) y, recientemente, a GonZÁLEZ (2006).

${ }^{51}$ La transparencia es un elemento fundamental. Muchas veces, la manera obvia de contribuir a evitar el problema real de los conflictos de interés, cual es el del actuar sesgado respondiendo a intereses ajenos a los que corresponde maximizar, radica en la diseminación y acceso informativo oportuno, adecuado y fácil. Otro elemento que suele enfatizarse como remedio, como ocurre con la regulación basada en restricciones y prohibiciones, muchas veces está lejos de ser inocuo en cuanto a los costos de todo tipo que involucra, sin mencionar las dudas respecto de su utilidad práctica. Más allá de la imagen, lo cual importa, a veces el problema no es el estar en una situación de eventual conflicto, sino la actuación sesgada misma en el desempeño de las funciones.

52 Entrevista a Eduardo Bitrán, ministro de Obras Públicas, La Tercera, 13/8/2006.

53 Entrevista a Eduardo Bitrán, ministro de Obras Públicas, El Mercurio, D7, 15/10/2006. La situación que motivó la entrevista dice relación con el hecho de que hasta el momento de asumir en el Ministerio de Obras Públicas, el ministro era director y asesor estratégico de Transelec, firma canadiense de transmisión eléctrica, la cual sería beneficiada con la servidumbre pertinente por el discutido trayecto vial fijado por el Ministerio. Sara Larraín, representante de un grupo ecologista y ex candidata presidencial, manifestó en la misma entrevista-reportaje que "no es adecuado que un ministro tome decisiones que favorecen a la empresa con que se relacionó". Por su parte, el senador del Partido Socialista, Ricardo Núńez, planteó que "[e]n forma independiente de que tenga de él la mejor opinión desde el punto de vista de la probidad, es 
no es inocua ${ }^{53}$. Reflejándose hasta dónde puede llegar la extralimitación en la argumentación sobre captura y conflictos de interés, dicho ministro expresó que "considero bajas estas acusaciones sobre conflictos de interés que yo pueda tener hoy. ¡No tengo ninguno! (...) me es bastante enojoso y molesto este tipo de insinuaciones. Estoy actuando como ministro exclusivamente en el interés del sector que hoy día me toca dirigir”. Y, finalmente, dejando entrever que los personeros públicos pueden responder a incentivos que van más allá de la mera satisfacción del interés propio, como pueden ser los intereses morales, plantea que "[c]ada una de las personas que menciona son profesionales éticamente impecables y me parece de mal gusto insinuar supuestos conflictos de intereses. No creo en lo que se está diciendo, que las únicas personas que podrían eventualmente ejercer cargos públicos son aquellas que nunca hayan tenido participación en el sector privado. Eso me parece ridículo.”.

Hasta aquí se ha hablado de la captura del Estado (y la regulación) por el poder privado y, en particular, por el poder económico representado en el empresariado. Sin embargo, en el debate público chileno el tema de la captura tiene una segunda acepción: la captura del Estado por el Gobierno, sus partidos y sus representantes políticos. En este tipo de captura la lógica general sigue siendo similar a la sustentada por las teorías del interés privado, no obstante, aquí el protagonismo no lo tienen aquellos grupos de interés provenientes del sector privado demandantes de rentas, sino más bien los actores políticos oferentes de rentas con fines de lucrativos privados y/o de carácter electoral. En la "captura por los políticos (de gobierno)" el temor radica en la utilización de los recursos del Estado (incluida las empresas públicas) con fines de intervención electoral y, en general, de clientelismo.

En un Estado sumamente presidencialista y en que el sector público sigue manejando una cantidad importante de recursos, no resulta osado sostener que una importante fuente de oportunidades para capturar rentas se encuentra en dicho ámbito más que a nivel de gestación de leyes, donde el poder parlamentario se encuentra muy limitado ${ }^{54}$.

De hecho, en los últimos años la mayor preocupación en materia de desplazamiento del interés público por intereses particulares ha estado en los actos de corrupción por parte de funcionarios y políticos de gobierno con aparentes fines de intervención electoral. Además de las irregularidades detectadas en la operación del Ministerio de Obras Públicas en administraciones pasadas, la aparición de desvíos de fondos en proyectos eminentemente sociales como en los casos de los planes de empleo y Chiledeportes ${ }^{55}$ ha colocado en un

absolutamente lógico plantearse si existe conexión entre la decisión y el interés que él debe haber tenido en su momento a propósito de la instalación de estas centrales en Aisén (sic). Es lógico que surjan las preguntas que mucha gente se formula”.

54 Parece no ser casualidad que en las últimas encuestas sobre corrupción elaboradas por el Instituto Libertad y Desarrollo las empresas públicas, las municipalidades y los ministerios encabecen el ranking de hechos de corrupción. Ver, por ejemplo, la última encuesta sobre corrupción de 2007.

55 LARroulet, Cristián, ha aludido a las irregularidades detectadas en Chiledeportes como un caso de captura del Estado por parte de grupos que lo utilizan para sus propios fines ("Chiledeportes y la 'Captura' del Estado”, La Tercera, 12/11/2006). 
lugar de importancia en la agenda pública del país el fortalecimiento de la probidad para atacar lo que se percibe como crecientes actos de corrupción en un país no acostumbrado a ello ${ }^{56}$.

Resulta curioso constatar, además, la existencia de una suerte de conexión entre los dos tipos de captura aludidos en este acápite. En efecto, han causado mucha repercusión las declaraciones de altos dirigentes de la coalición gobernante quienes últimamente han reconocido públicamente que "[d]esde el comienzo en la Concertación se pensó que, así como el dinero privado favorecía fundamentalmente a los partidos de derecha, no sería ilegítimo recibir financiamiento público a través de los recursos estatales para los programas sociales" 57 . En similar sentido a las recién transcritas palabras del ex senador y ex ministro Edgardo Boeninger, el ex presidente de la Cámara de Diputados y ex secretario general del Partido por la Democracia manifestó que "[y]o creo que se inventó una ideología para dar sustento y legitimidad a la utilización de los recursos públicos para fines políticos [con la que se] justifica que la Concertación, que en teoría no tiene acceso a recursos privados, use los recursos públicos para nivelar el campo de juego" 58 .

Continuando con las reflexiones de altos personeros de gobierno, pero esta vez volviendo a enfatizar la primera de las acepciones de captura estatal como prólogo a una visión histórica de este fenómeno en Chile, resulta útil rescatar el provocativo artículo de la revista The Economist. Tiempo atrás, dicho semanario enfatizó la diferencia que existe entre ser pro mercado y pro empresas ante un escenario que, según algunos autores aludidos por la revista, se caracterizaría por la existencia de un "Estado Cautivo" en donde las compañías han asumido el rol del gobierno o, en palabras de otro autor, han hecho una "compra silenciosa" de soberanía 59 . Comentando dicho artículo en una entrevista ${ }^{60}$, el ex ministro de Hacienda Nicolás Eyzaguirre reflexionaba que "[La revista The] Economist hace una diferencia que en Chile es poco socorri$\mathrm{da}-\mathrm{y}$ que a mi juicio, es muy importante- entre ser pro-market y pro-business, o sea estar a favor del mercado o favor de las empresas. Yo creo que soy más pro-market y eso a algunos les molesta. (...) Estamos llenos de pequeños grupos corporativos que han capturado al Estado y que han logrado que el Estado haga política para ellos y no para la ciudadanía ni para el bien común. Como es imposible que en una sociedad

\footnotetext{
56 En una línea similar a la anterior, aunque sin las características de escándalo público como los aludidos precedentemente, se ha mencionado el aprovechamiento electoral de instituciones gubernamentales como el Instituto Nacional de Desarrollo Agropecuario, INDAP.

57 Entrevista a Edgardo BOENINGER, El Mercurio, 3/12/2006.

${ }^{58}$ Entrevista a Jorge SCHAulsohn, El Mercurio, 10/12/2006.

59 The Economist, 26 de junio, 2003: "Pro-Market, Not Pro-Business".

${ }^{60}$ Revista Fibra, No 11, agosto 2003.

61 No obstante el aparente atractivo de la disyuntiva entre ser pro mercado y pro empresas, lo que llevó, luego de la publicación del citado artículo a extensas publicaciones de prensa en las cuales diversas personalidades se alineaban a un lado u otro ("yo soy pro empresa" "yo soy pro mercado”), podría, curiosamente, haberse generado la percepción de que aquellos pro mercados serían, precisamente, quienes tenían una mayor orientación a creer en la necesidad (y éxito) de la intervención reguladora del Estado en los mercados y viceversa, algo que no necesariamente es así si se atiende a la perspectiva histórica de nuestro país, como se apreciará más adelante.
} 
globalizada y competitiva les dé ciertas rentas o ciertos compartimentos protegidos a unos y no a otros, es el Estado el que paga la cuenta"61.

El comentario anterior, sin embargo, dista mucho de ser nuevo y la historia en algo parece avalar el predicamento o versión más "oscura” acerca del origen y de los fracasos de la regulación. De hecho, preguntémonos qué ocurría en Chile, por ejemplo, entre las décadas del treinta y setenta. En un ensayo publicado en 1980 y titulado "El Enriquecimiento de las personas en Chile: cuando ha beneficiado y cuando ha perjudicado al país" ${ }^{62}$, el en ese entonces decano de la Facultad de Economía de la Universidad de Concepción, Joaquín Lavín, claramente imbuido por el pensamiento imperante en la Universidad de Chicago, y apoyado con cierta evidencia empírica ${ }^{63}$, sostenía que "[hay que] distinguir la profunda diferencia que existe entre el enriquecimiento de grupos y personas dentro de un sistema económico intervencionista y discrecional, como el que Chile viviera en las últimas décadas, y el que por otro lado se registra en una economía libre sujeta a reglas objetivas e impersonales. [ ] En el primer esquema, el enriquecimiento de grupos y personas depende básicamente del favor que dispensa el poder político, y se hace a costa de perjudicar y empobrecer a otros. En el segundo, en cambio, él responde a la eficiencia de cada cual dentro de un esquema competitivo. Esto implica que la riqueza de una persona o grupo corresponde a su efectiva contribución al crecimiento económico del país. La riqueza así lograda no solo no se hace a costa de otros, sino que representa además un beneficio para el resto de los ciudadanos" 64 . Remarca dicho autor la apreciación anterior al afirmar que "[L]os casos de empresarios que trataron con éxito, de obtener favores del Estado se convirtieron en 'pan nuestro de cada día’ en el país. Desde 1930 en adelante pueden encontrarse en la legislación múltiples ejemplos de esta verdad"65.

En un sentido similar, Ernesto Fontaine comentaba que "[a]ntes eran 'ilegítimas' muchas de las fortunas conseguidas entre las décadas de 1940 y 1970 . ¿Quién podría admirar la riqueza alcanzada por quien 'consiguió' del gobierno de turno: una concesión monopólica; una cuota de dólares para importar a precio vil; créditos subsidiados; perdonazos; o, en fin, por alguien cuya fortuna fue 'conseguida' por favores y no por su imaginación, trabajo, ahorro y honradez?"66.

En un artículo en que la dimensión y perspectiva histórica se encuentra presente, Galetovic advertía en 1998 que "[l]a primera lección de las reformas [económicas del gobierno militar] que se está ignorando hoy en día es que el dinamismo que muestra la economía chilena se debe en gran medida a que en ella los mercados son libres -sin restricciones a la entrada y a la competencia-, las reglas son uniformes y las presiones de los grupos de interés no determinan la política económica". El autor subrayaba que "se ha perdido casi todo el impulso liberalizador, y, más aún, en muchos mercados se está

\footnotetext{
62 LAVÍN (1980).

63 Al respecto ver en particular lo expuesto por LAVín (1980) pp. 59-120.

${ }^{64}$ LAVÍN (1980) p. 123.

65 LAVÍN (1980) p. 18.

66 Fontaine: "Riquezas y valores sociales", El Mercurio, 29/10/1987.
} 
volviendo a prácticas que se parecen a las que fueron la norma hasta 1970: grupos de interés organizados presionan al gobierno para que este los proteja de la competencia con regulaciones que restringen la entrada, dificultan la competencia o suavizan la regulación del poder de mercado en industrias con características de monopolio natural. Este desarrollo es potencialmente mucho más dañino que la renuencia a privatizar. (...) Por otro lado, la debilidad con que el gobierno ha enfrentado las presiones de los grupos de interés sugiere que nuevamente se está tornando conveniente organizarse para exigir regulaciones que impidan la entrada y que restrinjan la competencia entre los que tienen el privilegio de ejercer una actividad determinada. (...) [B] rilla por su ausencia el interés por desregular y liberalizar mercados, en gran medida porque eso nunca le ha convenido a los grupos de interés organizados tanto empresariales como del sector público" 67 .

A modo de síntesis de lo anotado en el presente capítulo, en el cual, sin pretensiones de un recuento acabado, se ha intentado describir la presencia del tema de la captura en la argumentación pública chilena, se ha sugerido, en primer lugar, que la argumentación en virtud del cual se utiliza la noción de captura y el riesgo que esta conlleva está siendo utilizada con cierta frecuencia. En segundo lugar, se ha manifestado que el temor o las suspicacias están dirigidas tanto a la captura ejercitada por parte de las empresas como a aquella llevada a cabo por parte del gobierno, sus partidos o representantes políticos. En la "captura por los empresarios" el foco está puesto en la relación entre el dinero y la política. En la "captura por los políticos (de gobierno)" el temor radica en la utilización de los recursos del Estado (incluida las empresas públicas) con fines de intervención electoral y, en general, de clientelismo. En tercer lugar, y en parte como reflejo de lo anotado precedentemente, la noción de captura está muy presente en los debates respecto de la modernización del Estado en Chile, tanto en su asociación con la corrupción, como en la discusión del diseño regulatorio-institucional. En cuarto y último lugar, se ha intentado demostrar que la argumentación basada en el predominio del interés privado por sobre el público (en términos generales como respecto de la noción de captura en particular) no es en caso alguno nueva en Chile.

Como puede apreciarse, las provocativas teorías surgidas con fuerza en la segunda mitad del siglo pasado en Chicago y Virginia aún reverberan en los análisis actuales de las políticas públicas. Gran parte del análisis económico descansa en la racionalidad de los actores. El "Homo Economicus" no conoce de intereses y motivaciones que vayan más allá del frío cálculo racionalista de la maximización del interés privado. Cuesta negar, no obstante, el atractivo de tal aproximación a la regulación.

67 Galetovic (1998) pp. 146-147. Respecto de la debilidad con que, según el autor, el gobierno ha enfrentado las presiones de los grupos de interés, resulta ilustrativo lo relatado cinco años después por un reportaje de El Mercurio, el cual parece apoyar la apreciación por él emitida: "Grupos de presión/ El Estado capturado: Gobierno cede terreno a los intereses privados”, en el cual haciéndose uso del lenguaje aludido se subraya que "[e]nfrentado a los grupos de interés que presionan por lo que consideran sus derechos adquiridos, el Estado ha caído en la política de repartir la torta para mantenerlos tranquilos y así evitarse conflictos. Esto, a costa de todos sus representados". Constanze Kerber S.: El Mercurio, sección D, Reportajes, 5/9/2003. 


\section{ANÁLISIS CRÍTICO DE LAS TEORÍAS DEL INTERÉS PRIVADO}

¿Debemos quedarnos, sin embargo, con las teorías del interés privado como versión final de cómo debiera entenderse el origen, desarrollo y reforma de la intervención reguladora del Estado? ¿Está, acaso, detrás del fracaso de toda regulación la egoísta motivación de los actores en el mercado político o mercado por regulación?

Sin perjuicio del atractivo de examinar las políticas públicas o regulatorias en base a la preeminencia del interés privado de los diferentes actores en el mercado político o mercado por regulación, no parece convincente exagerar su poder explicativo y predictivo, o utilización como herramienta de análisis.

Una de las debilidades que se le atribuye a este modelo de reguladores o legisladores motivados por su interés particular (esto es, por su interés en ganar votos para su reelección en un cargo público, el cual les dará el poder para premiarse a sí mismo y a sus seguidores) y que en virtud de lo anterior "venden" protección legislativa a aquellos grupos de interés con mayores probabilidades de beneficiar su causa electoral, radica en su "indudable crudeza", como lo plantea $\operatorname{Hood}^{68}$. Hay que reconocer que la lógica del modelo es lúcida y atractiva para explicar los fenómenos regulatorios. Pero en su simple atractivo estriba también su debilidad.

Se ha criticado al modelo por su carencia de elaboración suficiente del proceso político. Se ha planteado, con justicia, que no se ha explicado la complejidad de diversas instituciones regulatorias, ignorando la anatomía de las instituciones políticas que proporcionan los diferentes tipos de regulación ${ }^{69}$. Existe una interesante literatura basada en el modelo principal-agente, en los costos de transacción, incluido los problemas de monitoreo y las asimetrías de información, entre otros, la cual no adhiere a la hipótesis de que la captura de la agencia reguladora es una condición permanente o inevitable, o que cuando ocurre se deba necesariamente a las interesadas motivaciones de todos los partícipes $^{70}$.

En un esfuerzo por probar empíricamente la solidez de una aproximación que destaque el riesgo de captura de los inspectores de la industria privada relacionada con la hospitalidad y cuidados del adulto mayor (nursing home) en Australia, Makkai y Braithwaite realizaron una investigación en virtud de la cual no se encontró evidencia concluyente de la existencia de captura en dicho sector ${ }^{71}$. Desde luego, lo analizado en un artículo no puede resultar en modo alguno decisivo. No obstante, dicho artículo da indicios de la importancia del contexto y situación de cada uno de los casos, lo cual limita la aspiración por apreciar el riesgo de captura como una realidad ineludible ante la ausencia de control.

Asimismo, se discute el supuesto racionalista e interesado de la actuación de los distintos involucrados. Como lo plantea Self ${ }^{2}$, hay hoy mucha evidencia de que el acto de

\footnotetext{
68 HoOd (1994) p. 23.

69 Para un recuento de este tipo de críticas véase a HäGG y GÖRAN (1997) p. 348.

70 HÄGG y GÖRAN (1997) pp. 351-354.

71 MAKKaI y BRAITHWAITE (1995).

72 SELF (1993) p. 46.
} 
votar no responde necesariamente a los intereses personales de carácter financiero; que las partes persiguen metas distintas que la maximización de votos; que los grupos de interés pueden crecer por otras razones que los incentivos económicos; que las burocracias no intentan siempre la maximización de sus presupuestos. Como el citado autor lo advierte, las teorías se equivocan debido a que ellas excluyen o subestiman otros importantes motivos en el comportamiento político, tales como las metas ideológicas y políticas, identificaciones emocionales y prejuicios, además de estándares y restricciones morales.

Mirados como modelos exploratorios (como a algunos teóricos les gusta considerarlos) estas teorías pueden incrementar el entendimiento de la política, pero pueden explicar el comportamiento solamente en contextos muy limitados. De hecho, una de las grandes dificultades de las teorías que, para estos efectos, hemos agrupados bajo la denominación de "Interés Privado", radica en explicar la ola de desregulaciones y privatizaciones producida a partir de la década del ochenta, fuertemente impulsada en el mundo bajo las presidencias de Reagan y Thatcher en EE.UU. y el Reino Unido, respectivamente ${ }^{73}$. Y ¿qué decir de lo ocurrido en nuestro país? ¿Puede entenderse adecuadamente la política económica del régimen militar chileno bajo la óptica de las aludidas teorías? Igualmente, y sin perjuicio de los esfuerzos académicos desplegados para defender la vigencia de las teorías del interés público, cabe destacar que así como estas teorías aparecen no del todo cómodas ante el fenómeno desregulatorio, tampoco lo están ante la dirección que ha tomado la regulación social, la cual, en algunas áreas, tal como la protección ambiental, ha devenido en una significativa expansión de controles intervensionistas favorables a los intereses difusos de los consumidores más que a los de los productores.

En fin, la captura del Estado puede ocurrir y resulta importante tener dicho fenómeno en consideración al momento de analizar una determinada política pública. Sin embargo, sería un error sobredimensionar su presencia, así como examinar las políticas regulatorias desde esa única perspectiva.

\section{LAS IDEAS Y LAS INSTITUCIONES TAMBIÉN IMPORTAN}

Como se adelantara precedentemente, para muchos resulta perturbador el supuesto básico de que la acción de los políticos y funcionarios públicos se encuentra estimulada predominantemente por motivos particulares. La intuición sugiere que la ideología y el altruismo pueden ser también importantes.

De hecho, tanta influencia han tenido las teorías del interés privado en nuestro país (recuérdese la influencia de los "Chicago Boys" en la génesis de la política económica del régimen militar) ${ }^{74}$, que plantear una suerte de "autoderrota” como teoría descriptiva (frente a su utilidad como aproximación -prescriptiva- de cómo hacer política pública) pareciera no ser descabellado.

\footnotetext{
73 PeLTZMAN (1989) p. 3, reconoció que "ni uno en cien economistas que hubiesen estado ejerciendo en los comienzos de 1970 predijeron los profundos y generalizados cambios que iban a ocurrir muy pronto...".

${ }^{74}$ Ver "El Ladrillo": Bases de la política económica del gobierno militar chileno.
} 
En el análisis de las políticas públicas los economistas, en general, han sido muy decisivos y podría haber mucho que agradecer al respecto. No obstante, y tal como lo plantea uno de los más célebres economistas del siglo XX, John Maynard Keynes, "[L]as ideas de los economistas y las de los filósofos políticos, tanto cuando son acertadas como cuando son erróneas, son más poderosas de lo que generalmente se cree. De hecho el mundo está gobernado por poco más que esto... Estoy seguro de que el poder de los intereses creados está notablemente exagerado, comparado con el de la gradual incorporación de las ideas"75.

En el caso chileno, las ideas de libertad económica, de libre competencia, de apertura de los mercados, de la necesidad de reglas generales y no discriminatorias, etc., llevaron a que en nuestro país se instaurara un sistema de economía de mercado antes inexistente y que se ha mantenido, con matices más o menos profundos, hasta el día de hoy. La aspiración (ideológica si se quiere) a que los precios del mercado sean lo más reales posibles o, dicho de otra forma, lo menos mentirosos posibles, permitió percibir que muchísimas de las regulaciones vigentes en Chile a mediados de la década del setenta eran no solo innecesarias, sino abiertamente nocivas. Hasta hoy causa cierta sorpresa aquel voluminoso documento escrito por los "Chicago Boys" bautizado como "El Ladrillo" y que desde el día siguiente al 11 de septiembre de 1973 comenzó a difundirse entre algunos militares del área económica. Como lo reconoce hoy un comentarista de autodefinida simpatía por la coalición gobernante de centro-izquierda, "lo impactante [de El Ladrillo] es que resultó ser un retrato hablado, no del Chile de 1990, sino del Chile del 2006 (...) y con un nivel de detalle inconcebible. Se le erizan a uno los pocos pelos. Rara vez un grupo académico ha tenido tal impacto en la transformación de un país"76.

En el caso norteamericano, la política de desregulación llevada a cabo en la presidencia de Reagan es mejor explicada, según Derthick y Quirk, atribuyéndolo al poder de las ideas ${ }^{77}$. En el mismo sentido, Harris y Milkis destacan el rol de liderazgo desempeñado por las elites intelectuales y políticas en el establecimiento de un nuevo régimen regulatorio. ${ }^{78}$ Estos últimos autores han sostenido que "nosotros debiéramos apreciar las ideas e instituciones subyacentes si hemos de entender la desregulación resultante de la revolución de Reagan"79.

La explicación basada en el poder de las ideas, sin embargo, no explica por sí sola por qué en un momento histórico determinado unas ideas y no otras prevalecen. ¿Por qué, por ejemplo, las autoridades militares chilenas, a diferencia de sus pares sudamericanos, optaron por seguir un modelo distinto ${ }^{80}$.

\footnotetext{
75 KEYNES (1936).

76 Waissbluth, Mario “¿Necesitamos un nuevo Ladrillo?”, artículo de opinión, Revista Qué Pasa, 27/5/ 2006.

77 DERTHICK y QUIRK (1985).

${ }^{78}$ HARRIS y MILKIS (1996) p. 25.

${ }^{79}$ HARRIS y MILKIS (1996) p. 18.

80 Como lo manifiesta FonTAine (1993) p. 246, "[1] os economistas de libre mercado tenían una visión verdaderamente revolucionaria. Pretendían derribar el sistema económico imperante y construir uno totalmente nuevo. Y no le temían a ningún grupo de interés opuesto a las reformas. El valeroso intento de
} 
No obstante lo anterior, posiblemente constituiría una falta desestimar la fuerza de las ideas como elemento explicativo de fenómenos sociales, entre ellos, las políticas de regulación. Una atenta mirada a la historia no permite desechar la advertencia contenida en la alusión hecha por Isaiah Berlin en su famoso ensayo de 1958 "Two Concepts of Liberty": "Hace más de cien años, el poeta alemán Heine advirtió a los franceses no subestimar el poder de las ideas: conceptos filosóficos alimentados en la tranquilidad de la oficina de un profesor podría destruir una civilización" 81 .

¿Y qué se puede decir de las instituciones como elemento formador de los comportamientos regulatorios? Para las teorías institucionales, más relevantes que los intereses (cuya influencia no se desconoce) son las normas, reglas y arreglos sociales y organizacionales, los que perfilan y dan forma a la regulación. Para North, las instituciones son "las reglas del juego", las cuales asumen dos formas: reglas formales, tales como las constituciones, las cuales son útiles para codificar las reglas que rigen el funcionamiento de una sociedad y su economía; y los códigos o reglas informales de comportamiento. Como lo enfatiza el autor citado, "[m] ientras que las reglas formales pueden cambiarse de la noche a la mañana por la comunidad, las restricciones informales cambian muy lentamente. Ambas son moldeadas en última instancia por las percepciones subjetivas de la gente sobre el mundo que los rodea" 82 . Según nos lo comenta Grossman "es posible que los códigos informales ejerzan una influencia más fuerte sobre el comportamiento que las leyes formales. Puede promulgarse una ley que concede, digamos, derechos de propiedad a un individuo, pero dicha ley carecerá de sentido si va en contra de las normas de la propiedad comunal o será aplicada solo muy lentamente a medida que evolucionen las creencias en términos de qué es legítimo y qué no lo es" 83 . En el fondo, la perspectiva institucional plantea que, sin perjuicio de la influencia de los grupos de interés en moldear la regulación, esta adquiere forma (en términos de formulación y enforcement) en parte importante según las características de las instituciones existentes $^{84}$. En otras palabras, el "espacio regulatorio" generado por las instituciones actúa como marco en el cual juegan diferentes intereses u organizaciones de modo similar, podríamos decir, a como el recipiente le da forma al agua en él contenida ${ }^{85}$.

comenzar una nueva etapa en la historia del país se ganó la simpatía de algunos militares, especialmente del general Pinochet. Pero las simpatías se acababan ahí. Debido a su entrenamiento profesional, los militares tenían una visión nacionalista de la economía. Las políticas proteccionistas les parecían más propicias para la seguridad nacional que las propuestas de libre comercio".

${ }^{81}$ La publicación de dicho artículo puede verse en BERLIN (1997) pp. 191-242.

82 NORTH (2003) p. 1.

83 Grossman (1994) pp. 22-28.

${ }^{84}$ Para una síntesis de las teorías institucionales ver a BALDWIN y CAVE (1999) pp. 27-31.

85 Se enfatiza que la regulación económica es una regulación predominantemente por organizaciones y a través de organizaciones. Una perspectiva organizacional de la regulación permite ir más allá de la teoría de la captura. Resulta esencial examinar el proceso por el cual organizaciones poderosas (estatales y no estatales) ganan, mantienen o pierden posiciones de dominancia en el espacio regulatorio. Bajo la perspectiva indicada, la relación agente-principal suele ser objeto de estudio. Ver sobre el particular a HANCHER y MORAN (1989). 


\section{HASTA QUÉ PUNTO LA TEORÍA DEL INTERÉS PÚBLICO DE LA REGULACIÓN SE ENCUENTRA DESACREDITADA}

¿Es posible sostener que alguna de las teorías generales aludidas puede explicar, en exclusividad, los procesos y comportamientos regulatorios? ¿Qué tan apropiada es la afirmación de que las explicaciones funcionalistas o del interés público debieran ser rechazadas como un factor de utilidad para dilucidar las motivaciones de una política regulatoria debido a que dejarían demasiadas cosas sin explicar?

Indudablemente que no es fácil la tarea de explicarse la realidad inquiriendo las motivaciones o causas de un evento, tales como el origen y manifestación de las políticas regulatorias. Si es difícil develar las causas de los fenómenos naturales, lo es aún más cuando el objeto de análisis pertenece a las ciencias sociales. Si, como lo apunta North, toda teorización acerca de las ciencias sociales se construye, implícita o explícitamente, sobre concepciones del comportamiento humano ${ }^{86}$, no es difícil intuir los desafíos presentes para las ambiciosas teorías que hemos descrito sucintamente.

Una de las cosas que más llama la atención es la pretensión de generalidad y exclusividad con que, en términos generales, son expresadas las distintas teorías. Lo cierto, es que resulta más convincente argumentar que cada una de las teorías tiene algo de razón, lo que significa, igualmente, que todas resultan incompletas en su aspiración de explicar el origen, desarrollo y extinción de una política regulatoria. En este sentido, la crítica de las teorías funcionalistas o normativas consisten (además de su carácter teleológico) en su fracaso para demostrar cuáles son las fuerzas políticas que podrían conducir a un gobierno a actuar de una manera beneficiosa para el interés general, también puede hacerse a las otras en lo que respectas a su visión incompleta de la realidad. En efecto, recurrir solo a los intereses, o a las ideas, o a las instituciones, por mencionar las reseñadas, proporciona una visión parcial del fenómeno regulatorio. En cierta forma, todas las aproximaciones indicadas pueden coexistir unas con otras, sin perjuicio que en determinados momentos históricos una o dos pueden resultar especialmente apropiadas para explicar los acontecimientos regulatorios.

En general, un evento es susceptible de ser explicado no solo desde diferentes perspectivas, sino también desde diferentes niveles de generalidad. De hecho, antiguos filósofos como Aristóteles reconocían la posibilidad y necesidad de tomar en consideración diferentes aproximaciones o causas para conocer y explicar algo ${ }^{87}$. Esto es igualmente verdadero para el tópico bajo análisis, donde es posible advertir que las diferentes teorías tratan de explicar el fenómeno en base a causas menos o más inmediatas (primarias), así como desde diferentes campos del conocimiento.

La teoría de Chicago, por ejemplo, enfatiza la motivación egoísta e interesada de los actores en el proceso regulatorio. Obviamente, la recién aludida aproximación basada en la orientación de búsqueda de riqueza de las personas y grupos (rent-seeking activities) podría ser atacada de falta de consideración por los aspectos culturales, institucionales o

86 NORTH (1990).

${ }^{87}$ IRWIN (1990). 
ideológicos. Del mismo modo, la teoría que descansa en el poder de las ideas si bien está basada en una construcción intelectual con mayor nivel de generalidad que aquella que destaca la satisfacción de los intereses privados, implica una atención imprecisa a las causas que dan lugar a cualquier política regulatoria particular, donde la presencia de poderosos grupos de interés podría ser encontrada. En definitiva, los diferentes niveles de análisis mostrados por las diferentes teorías explican la posibilidad de complementariedad entre ellas para poder explicar una cierta política pública.

Es cierto que resultaría ingenuo creer que cualquier justificación es susceptible de proporcionar los reales motivos de una intervención regulatoria por parte del Estado. No obstante, sería extraordinariamente radical postular que las razones de interés público declaradas por los reguladores son siempre una ficción. Además, una justificación, la cual puede ser también una explicación, muchas veces puede ser considerada como una causa final, esto es, la meta última hacia el cual el proceso tiende. De hecho, saber el objetivo final que inspira una política, la que muchas veces está basada en la buena fe, puede proporcionar una comprensión invaluable del proceso.

El mal resultado de una regulación no puede constituir plena prueba en contra de la dimensión de interés público, debido a que nadie puede asegurar el éxito de la misma. Como Breyer sugiere, "Es probable que incluso el mejor intencionado de los reguladores encuentre difícil o imposible llevar a cabo una regulación según el mandato legal; [...incluso más] entender los obstáculos en el camino del bien intencionado regulador puede, entonces, ayudar a iluminar, aunque no explicar plenamente, una acción regulatoria" 88,89 .

A mayor abundamiento, la necesidad de prestar atención a justificaciones o categorías normativas surge también de la búsqueda de estándares en contra de los cuales juzgar los méritos o deméritos de un programa regulatorio.

Finalmente, aunque se pueda sostener que la teoría del interés público carece de poder predictivo al ignorar la existencia de las fuerzas políticas capaces de conducir al gobierno a regular de una determinada manera, no debe olvidarse que cuando la palabra "explicación" es utilizada no está haciendo alusión a su poder predictivo. Resultaría difícil atribuir éxito en la capacidad de predicción a las otras teorías en competencia. De hecho, y tal como ironiza $\mathrm{McClosky}^{90}$, un economista, más que predecir, es alguien que puede decir mañana por qué las profecías de ayer no se avienen con los acontecimientos de hoy día ${ }^{91}$.

\footnotetext{
88 BREYER (1982) p. 10.

89 Algunos como HAYEK (1985) intentan encontrar la explicación del fracaso de una regulación en las limitaciones del conocimiento humano. Este planteaba que es imposible prever anticipadamente toda la variedad de circunstancias en la cual regulaciones específicas deben ser aplicadas. No es posible que exista un pool central de información en base al cual los reguladores puedan confiar para la elaboración de las políticas reguladoras. Así, pues, HAYEK estaba convencido que la idea de usar la ley para propósitos instrumentales específicos era ilusoria.

${ }^{90}$ MCClOSKy (1985) p. xix; citado por HoOd (1994).

${ }^{91}$ Lo mismo podría decirse de los abogados si se entusiasmaran con ese tipo de actividades.
} 


\section{CONCLUSIONES}

El origen de la intervención reguladora del Estado puede ser discutido en términos de justificaciones y/o explicaciones. Una explicación intenta descubrir los motivos o razones en virtud de los cuales una determinada intervención reguladora existe; una justificación intenta decir por qué una determinada regulación es una buena idea. Afortunadamente, en algunos casos una explicación es a veces una justificación también ${ }^{92}$. Una política reguladora puede tener su explicación (en el sentido en el que estamos usando tal término) en razones que están muy lejos de fortalecerla o darle brillo. Estas pueden obedecer, por ejemplo, al comportamiento de ciertos grupos de interés que buscan "capturar" al Estado logrando que una determinada legislación o política les sea favorable, sin consideración al interés público. Es lo que algunos denominan como transferencia de riqueza a grupos de interés y que, dicho sea de paso, constituye una de los más significativos aportes de la escuela de Chicago y de la escuela de Virginia.

En el presente trabajo se ha destacado que la visión clásica propia de la teoría del interés público era entender que la motivación o explicación de la intervención del Estado en los mercados se debía a la existencia de fallas de mercado (market failure). Sin embargo, resulta evidente que no solo el mercado puede fallar, sino también la regulación o el Estado, fracaso que si bien puede dejar incólume la buena fe de los actores públicos en la satisfacción del interés público en la formulación y aplicación de la regulación, también admite una visión menos ingenua, si se quiere. Se ha remarcado que, muchas veces, las razones de por qué una regulación fracasa en su intento de remediar una imperfección de mercado y promover el interés público distan mucho de ser enaltecedoras. Es decir, el origen, desarrollo y extinción de una intervención reguladora del Estado puede obedecer a la preeminencia de intereses privados por sobre los públicos de parte de legisladores, reguladores, funcionarios públicos, empresas reguladas y ciudadanos votantes, según el caso.

Se analizaron aquellas primeras teorías de la captura enfocadas en la progresiva identificación de quienes fiscalizan con aquellos fiscalizados. Se hizo hincapié en la aproximación económica de la regulación, la cual considera a esta como un bien susceptible de ser transado en un mercado en el cual los diferentes actores actúan movidos por la búsqueda de su satisfacción pecuniaria personal o del grupo al cual pertenecen. Junto con reconocerse que la noción de captura y, en definitiva, de la preeminencia del interés privado por sobre el público tiene asidero en el análisis actual e histórico de las políticas públicas en Chile, se advierte que la noción de captura está lejos de ser no problemática y autosuficiente. De hecho, este artículo relativiza la suficiencia de las teorías del interés privado para explicar el comportamiento regulatorio y, en general, para entender y justificar orientaciones en materia de políticas públicas.

En efecto, las teorías del interés privado han proporcionado una perspectiva de extraordinaria utilidad que debe ser reconocida. Sin embargo, no debe olvidarse, como lo reconocen Buchanan y Tullock al reflexionar sobre los menores niveles de racionali-

92 SUNSTEIN (1990) p. 47. 
dad en los procesos de elección colectiva en comparación con los de actuaciones individuales, que "todos los modelos lógicos son limitados en su capacidad de ayudar en la explicación del comportamiento"93. Como lo confiesa el primero de estos, "[d]ebería ser evidente que el análisis básico de la elección pública (public choice) no puede aplicarse para explicar los cambios en las reglas básicas del orden político si no se reconoce la existencia de algo más que el interés privado y egoísta en los individuos. Hay un punto indefinido, pero real, en el que las gentes sienten la preocupación por lo público y por lo general, o de otra manera no hay forma de concebir una transición no revolucionaria sino democrática de un punto a otro del orden social" 94 .

Aún más, se señala que para explicarse las causas y motivaciones del fenómeno regulatorio resulta indispensable tomar en consideración el poder de las ideas, así como la influencia de las instituciones. Se arguye que estas aproximaciones teóricas actúan con diferentes niveles de generalidad, lo que admite la posibilidad eventual que todas se complementen, sin perjuicio que, muchas veces, unas y no otras serán más idóneas y convincentes para explicar una realidad.

Se indicó que en el análisis de las políticas públicas nacionales abunda la suspicacia propia de asumir, como si fuera un dogma, la preeminencia del interés privado sobre el público, para lo cual, como se dijo, se suele aludir al término "captura". En el presente trabajo se aspira a mostrar el recorrido académico en la búsqueda de construcciones teóricas que permitan explicar el origen, desarrollo y extinción de las políticas regulatorias, ejercicio que coloca de manifiesto, en último término, el desafío de reconocer mas no sobredimensionar la utilidad práctica de la noción de captura, captura regulatoria o riesgo de captura. Los actores públicos y los ciudadanos pueden también regirse por motivaciones altruistas o de interés público. Muchas veces, las motivaciones ideológicas resultan fundamentales, del mismo modo que la producción y aplicación de las políticas regulatorias se forma, en parte, por las restricciones institucionales que puedan existir. Al final, tan peligroso como la captura, es el riesgo de quedar capturados por nuestra propia suspicacia.

\section{BIBLIOGRAFÍA CITADA}

BALDWIN, Robert y CAVE, Martin (1999): Understanding Regulation (Oxford, Oxford University Press) 363 pp.

BECKER, Gary (1983): "A Theory of Competition among Pressure Groups for Political Influence", Quarterly Journal of Economics, vol. 98 No 3: pp. 371-400.

BERLIN, Isaiah (1997): The Proper Study of Mankind: an anthology of essays (London, Chatto and Windus) $667 \mathrm{pp}$.

Bernstein, Marver (1955): Regulating Business by Independent Commission (Princeton, New York, Princeton University Press) 306 pp.

\footnotetext{
93 BuCHANAN y TUllock (1993) p. 66.

${ }^{4}$ BuChanan (1985) Liberty, Market and State, capítulo 9, citado por José Antonio Aguirre Rodríguez en su prólogo a la versión traducida al castellano de BRENNAN y BUCHANAN (1997) p. 31
} 
BREYER, Stephen (1982): Regulation and Its Reform (Cambridge, Massachusetts, Harvard University Press) $472 \mathrm{pp}$.

Buchanan, James y Tullock, Gordon (1993): El Cálculo del Consenso (traducc. Javier SALINAS SÁNCHEZ, Barcelona, Editorial Planeta - De Agostini) 394 pp.

BUCHANAN, James (1985): Liberty, market and state: political economy in the 1980s (Brighton, Wheatsheaf) 278 pp.

Brenan, Gordon y Buchanan, James (1997): La Razón de las Normas (traducc. José Antonio Aguirre RodrígueZ, Barcelona, Ediciones Folio) 191 pp.

Den Hertog, Johan (2000): “General Theories of Regulation”, en: BoucKaerT B. y De GEEST G. (edit.), Enciclopedia of Law and Economics, vol. III, The Regulation of Contracts (Cheltenham, Edward Elgar) pp. 223-270.

DerThick, Martha y QUIRK, Paul (1985): The Politics of Deregulation (Washington D.C., Brooking Institution Press) 266 pp.

Downs, Anthony (1957): An Economic Theory of Democracy (New York, Harper and Row) 310 pp.

Fontaine, Juan Andrés (1993): “Transición Económica y Política en Chile: 19731990”, Estudios Públicos No 50: pp. 229-279.

GAletOVIC, Alexander (1998): "Desatando a Prometeo: reformas microeconómicas en Chile: 1973-1989”, Revista Perspectivas vol. 2 N$^{\circ} 1$ : pp. 131-155.

GONZÁlEZ, Aldo (2006): "Estudio sobre la revisión de la institucionalidad regulatoria de los servicios sometidos a fijación tarifaria". Ministerio de Economía, sección Estudios, septiembre. Disponible en: <http://www.economia.cl/aws00/Estatico/repositorio/d/z/k/_4isvhAGNdf1f_FOpG31F3X8=.pdf> [fecha de consulta: 31 julio 2007].

Grossman, P. Z. (1994): “Douglass North: por qué algunas naciones logran sostener el desarrollo", Reforma Económica, Hoy, 3: pp. 22-28.

HÄGG, P. y GÖRAN T. (1997): “Theories on the Economics of Regulation: A Survey of the Literature from a European Perspective”, European Journal of Law and Economics, 4: pp. 337-370.

Hancher, Lee y Moran, Michael (1989): “Organising Regulatory Space”, en: L. HANCHER y M. Moran. (edit.), Capitalism, Culture and Economic Regulation (Oxford, Clarendon Press) pp. 271-300.

HARrIS, Richard y MiLKIS, Sidney (1996): The Politics of Regulatory Change: a tale of two agencies (New York, Oxford University Press) 432 pp.

HAYEK, Fiedrich (1985): Derecho, legislación y libertad. Una nueva formulación de los principios liberales de la justicia y de la economía política (Traducc. Luis REIG AlBIOL, Madrid, Unión Editorial) 556 pp.

Hellman, Joel y KaUfmann, Daniel (2002): “The Inequality of Influence”. Preliminary draft for presentation at Stanford Corruption Workshop, January 30-31, 2003. Disponible en: <www.worldbank.org/wbi/governance> (fecha de consulta: 31 julio 2007).

Hood, Christopher (1994): Explaining economic policy reversals (Philadelphia, Open University Press) 167 pp. 
InSTITUTO LiBERTAD y DeSARROLlo (1999): "Cambios a la institucionalidad reguladora", Temas Públicos, 434. Disponible en: <http://www.lyd.com/lyd/centro_doc/documents/tp-434-cambios\%20en\%20la\%20institucionalidad\%20reguladora-27-051999.pdf> [fecha de consulta: 31 de julio 2007].

IRWIN, Terence (1990): Aristotle's first principles (Oxford, Oxford University Press) 720 pp.

ILlANES, Ignacio e IGOR, Olivia (2007): "Encuesta de Corrupción 2007: percepción y realidad”, Libertad y Desarrollo. Serie Informe Politico, 101: pp. 1-41.

Kaufmann, Daniel y Vicente, Pedro (2005): “Legal Corruption”. Second draft. Disponible en: <www.worldbank.org/wbi/governance.> [fecha de consulta: 31 julio 2007].

KEYNES, John Maynard (1936): The General Theory of Employment, Interest and Money (New York, Hartcourt, Brace and World) 413 pp.

LAVÍN, Joaquín (1980): El Enriquecimiento de las personas en Chile: cuando ha beneficiado y cuando ha perjudicado al país (Concepción, Ciencia y Tecnología) 124 pp.

LeVine, Michael (1998): "Regulatory Capture", New Palgrave Dictionary of Economics and the Law, 3: pp. 267-271.

Majone, Giandomenico (1996): Regulating Europe (London y New York, Routledge) $301 \mathrm{pp}$.

MAKKai, T. y BRAithwaite, J. (1992): "In and Out of the Revolving Door: Making Sense of Regulatory Capture", Journal of Public Policy, vol. 12 No 1: pp. 61-78.

MCCLOSKY, Donald (1985): The Rethoric of Economics (Madison, Wisconsin, Wisconsin University Press) 209 pp.

MitChell, William (2001): "The old and new public choice: Chicago versus Virginia”, en: Shughart, William F. y Razzolini, Laura (edit.), The Elgar Companion to Public Choice (Cheltenham, UK y Northhampton, M.A., USA, Edward Elgar) pp. 333.

Mueller, Dennis (2003): Public Choice III (Cambridge, U.K., Cambridge University Press) $768 \mathrm{pp}$.

NorTH, Douglass (1990): Institutions, institutional change and economic performance (Cambridge y New York, Cambridge University Press) 152 pp.

NORTH, Douglass (2003): "Instituciones, Ideología y Desempeño Económico", Cato Journal Vol. 11 No 3: 477-488. Disponible en: <http://www.elcato.org/node/1272/ print> [fecha de consulta: 31 julio 2007].

Ogus, Anthony y Veljanovski, Cento (1984): Readings in the economics of law and regulation (Oxford, Oxford Clarendon Press) $361 \mathrm{pp.}$

OguS, Anthony (1994): Regulation: legal form and Economic Theory (Oxford, Clarendon Press) 355 pp.

OGUS, Anthony (2004): "W(i)ither the economic theory of regulation? What economic theory of regulation?", en: JORDANA Jacint y LEVI-FAUR David (edit.), The Politics of Regulation: Institutions and Regulatory Reforms for the Age of Governance (Cheltenham, UK and Northampton, MA, USA, Edward Elgar) pp. 31-44. 
Olson, Mancur (1965): The Logic of Collective Action: Public Goods and the Theory of Groups. (Cambridge, M.A., Harvard University Press) 176 pp.

Paredes, R., Sanhueza, R. y Letelier, L. (1998): "Autonomía de las instituciones gubernamentales de Chile”. Documento de Trabajo R-344, Red de Centros de Investigación. Disponible en: <www.iadb.org/res/publications/pubfiles/pubr-344.pdf> [fecha de consulta: 31 julio 2007].

Peltzman, Sam (1976): “Toward a more General Theory of Regulation”, Journal of Law and Economics, vol. 19: pp 211-240.

PeLTzMan, Sam (1989): “The Economic Theory of Regulation after a Decade of Deregulation", Brookings Papers on Economic Activity: Microeconomics: pp. 1-41.

POSNER, Richard (1974): “Theories of Economic Regulation”, The Bell Journal of Economics and Management Science, vol. $5 \mathrm{~N}^{\circ} 2$ : pp. 335-358.

SAAVEDRA, Eduardo y SOTO, Raimundo (1999): "Modernización Institucional del Estado: Reflexiones para la Discusión”. Documento de trabajo, Universidad Alberto Hurtado. Disponible en: <http://economia.uahurtado.cl/pdf/publicaciones/e-21.pdf> [fecha de consulta: 31 julio 2007].

SELf, Peter (1993): Government by the Markets? The Politics of Public Choice (London, Macmillan) $295 \mathrm{pp}$.

STIGLER, George (1971) “The Theory of Economic Regulation”, Bell Journal of Economics and Management Science, vol. 2 No 1: 1-21.

STIGLER, George. (1987) "Los Viajes del señor Smith en el barco del Estado", en: El Economista como Predicador y otros Ensayos (Traducc. Jorge PASCUAL, Barcelona, Ediciones Folio, Barcelona), volumen II, capítulo 12, pp. 54-69.

Sunstein, Cass R. (1990): After the Rights Revolution: Reconceiving the Regulatory State (Cambridge, Mass. y London, Harvard University Press) 284 pp.

Tullock, G., Seldon, A. y Brady, G. (2002): Government Failure. A primer in public choice (Washington, D.C., Cato Institute.) 193 pp.

"El Ladrillo": Bases de la política económica del gobierno militar chileno, Disponible en: <www.cepchile.cl> (fecha de consulta: 31 julio 2007).

The Economist, June 26th, 2003: "Pro-Market, Not Pro-Business".

Revista Fibra, No 11, Agosto, 2003.

Revista Qué Pasa.

Diario El Mercurio.

Diario La Tercera. 
